\title{
English Teaching and Learning in a Korean University Perceptions of International Professors
}

\author{
Sang Ho Han \\ singhap@gu.ac.kr \\ Logos College, Gyeongju University \\ Gyeongju, South Korea
}

$\begin{array}{ll}\text { Article History } & \\ \text { Received: } & 05 / 18 / 2020 \\ \text { Reviewed: } & 06 / 03 / 2020 \\ \text { Accepted: } & 07 / 07 / 2020\end{array}$

Keywords:

faculty perception, view of language, view of language learning, English teaching/learning philosophy, ELT innovation

DOI:

$\underline{\text { https://doi.org/10.33508/bw.v8i2.2513 }}$

\begin{abstract}
The purpose of this study is to investigate the perceptions of international faculty towards English teaching and learning at a local university in South Korea. For data collection, a comprehensive questionnaire was administered on a google survey to 71 international faculty teaching at the university. The survey consisted of items of questions concerning faculty's second language learning experience, teaching/learning philosophy, and teaching techniques and skills. Description of the responses revealed the following results: 1) Second language learning experience of faculty helps improving quality of instruction through understanding students' learning difficulties; 2) Faculty's view of language was mostly holistic while that of language learning was inclusive of different perspectives; 3 ) The role teachers was mainly that of a facilitator in a student-focused class; 4) For those applying CLT, it was used to engage students within a student-centered classroom; 5) A general maxim of teaching was the golden rule: "Do unto others, as you would have done unto you."; 6) Views on teaching explicit knowledge varied widely among faculty; 7) The majority of faculty chose to correct both global and local errors; 8) A number of strategies were utilized in order to help students overcome reluctance to speak; 9) In order to enhance students' communicative abilities, a suggestion was made for innovation of general English education programs.
\end{abstract}

\section{Introduction}

In line with the trends of globalization international faculty force in order to and internationalization, the G University, improve the status of English education at which is located in the Southeastern part of the university. The students enrolled in the Republic of Korea, has been increasing the said university were not highly motivated 
toward English learning and communication and their perceived level of English proficiency was mainly low to low intermediate.

It was believed by the school administration that employing more native speaker or international professors would guarantee success of English education. This resulted in hiring more such faculty and securing more contact hours for students both in and out of English mediated classes. In the spring semester of 2012, more learner-friendly general English education courses have begun to supersede TOEIC listening and Reading classes, which were the main English courses at the school for many years in the past.

The names of newly introduced courses included Sure Talk, Enjoy Talk, Talking over Aroma of Coffee, English through Popular Music, English through Sports, English over Wine, English through Famous Speech, English through Mythology, Tips for Overseas Travel, English for International Etiquettes, and Understanding Multi-culture, etc. The names of these student-friendly courses were mostly the creation of brainstorming on the part of participating international faculty. As many as 18 sections of the same courses were offered to students in order to provide more contact hours within the class. At the same time, English lounge and international faculty one-to-one communication mentoring was extensively provided in areas labeled as English lounge for more personalized English learning opportunities.

With the number of native and international faculty exceeding the total of 80 , the atmosphere of the university campus began to change into more global especially around the building where most English mediated course were taught. This has allowed more time for reflection and sharing on the part of the faculty as to teaching methods and ideas of teaching. With this change of air on the campus, a proposal was made by international faculty coordinator for professional development of international faculty. The dynamic and diverse nature of the faculty culture was considered unique and it was thought sharing of the various experiences and perspectives would serve to contribute not only to the school they were working at but also to enhancement of the English education professionals in Korea as well.

The purpose of this study is to investigate the perceptions of English teaching from those who were rendering service at the said university. The survey questions were designed to elicit the respondents' teaching experience, teaching/learning philosophy, and perceptions about their teaching approach toward communicative teaching methods. All international faculty were invited to input their thoughts and ideas in a google survey form created by a software engineerturned English professor, and provided by the coordinator.

\section{Review of Literature}

Studies on teacher beliefs have shown that they have a significant impact on teaching practice, and provide rationale for what teachers do in the classroom. That is, teachers' beliefs function as a core reference point during the course of teaching, and provide a basis for actions and behaviors. This is well stated in Richards and Lockhart (1994):

"What teachers do is a reflection of 
what they know and believe, and that teacher knowledge and 'teacher thinking' provide the underlying framework or schema which guides the teachers' classroom actions." (p. 29).

This statement illustrate the notion that teachers' classroom actions reflect what teachers know and think, and this knowledge and thinking is a product of their previous learning experiences, and thus may be "personalized, idiosyncratic, and highly context specific" (Tusi, 2003, p. 61). Teachers tend to do things that they have observed; in what Lortie (calls) an "apprenticeship of observation" suggesting that teachers internalized their observed behavior and this strongly influences their teaching practices. Thus what teachers do in the classroom cannot be fully understood without considering what they bring into the classroom, what they believe about learning and teaching, and how their beliefs are received in the classroom.

The majority of studies on teacher/student beliefs used Horwitz's (1985) 34-item self-report questionnaire, BALLI, to assess the beliefs of teachers and learners. Peacock (1999) compared the beliefs of 202 students and 45 university ESL teachers and found noticeable differences in their beliefs about vocabulary and grammar. While students believed that learning a foreign language is a matter of learning a lot of new words and grammar rules, only a small percentage of teachers agreed. Saminy and Lee (1997) found similar results in a study of 34 students and 10 teachers. On the other hand, Breen (1991) observed that even the most experienced teachers in a master's program considered language as a system rather than a means of communication despite their theoretical training. Kagan (1992) also found similar results in her review of 27 empirical studies on student teachers' beliefs about learning.

The personal nature of the teacher beliefs was researched by Breem, Hird, Milton, Oliver and Thwaite (2001). Through multiple classroom observations and subsequent interviews of 18 ESL teachers, they argue that some of the teachers' seemingly identical classes are based on each individual teacher's fundamentally different belief about learning and teaching. They also argue that a complex relationship is involved between teachers' beliefs and their realization into actual classroom teaching within particular classroom circumstance (Choi, 2006).

With the exception of a few studies (Feryok, 2008; Gu, 2010), however, more attention has been paid to the beliefs of preservice teachers, and relatively little research has been conducted with practicing teachers, especially with the NS teachers in the EFL context. Based on semi-structured interviews and questionnaires with British specialists and Chinese teachers participating in a teacher training program, $\mathrm{Gu}$ (2010) concluded that teachers learn from their experiences and gradually develop their competence as experts, and their growth of expertise is situation specific reflecting cultural characteristics. Similarly, Shin (2002) conducted interviews over a ten month period with seven Asian teachers (Korean, Japanese, Taiwanese, Chinese) who were enrolled in doctoral programs in the United States, and found that the participants perceived their role as a friendly caregiver, which was the opposite image of a teacher as an authority figure in their traditional education system (Kim, 2011). While these studies described Asian and NS teachers' beliefs about learning and their perception of problems in the EFL classrooms, they did not describe how the 
individual teacher's previous learning and teaching experiences and their cultural background have contributed to their beliefs about learning and teaching.

As a result of previous research studies on teacher perceptions, it was found that more attention has been paid to the beliefs of pre-service teachers and relatively little research has been conducted with practicing teachers, especially with the NS teachers in the EFL context. Chin (2002) is one of the few studies on NS teachers' beliefs in the EFL context. Using interviews and questionnaires with 18 EFL teachers at a suburban area in Gyeongsangnamdo province, she found that native speaker professors considered language learning as learning communication skills. She also found that these professors considered students' lack of confidence in English and their perfectionist complex to be the major obstacles to improving their i. Finally, they believed that making mistakes is necessary in second language learning and thus viewed their role as creating an environment in which students can participate in communication. The current study will verify what these native speaker teachers had said with analysis of multiple responses from 71 faculty who were teaching in the researched university.

More recently, Kim (2011) studied the NS teachers' beliefs on learning and teaching, based on survey and interviews from eight native speaker professors. Her study was conducted with reference to their educational and cultural background, and found that, similar to Chin's (2002) findings, the NS teachers believed that learners' active participation in classroom interaction, making mistakes, and taking responsibility for their own learning serve as core elements of second language learning. She further argued that such beliefs were closely related to the teachers' own learning experiences gained in their home contexts, and their theoretical or practical knowledge acquired through their teacher training or prior teaching experiences.

However, both Chin (2002) and Kim (2011) dealt with the perceptions of NS teachers from inner circle countries such as USA, England, Canada, and Australia, and did not include perspectives of non-native international faculty who are teaching English in Korea. The current study investigates perceptions of 71 native and/or international faculty through a comprehensive closed and open-ended survey, and tries to verify Chin's and Kim's findings from NS professors, while trying to complement those views and perspectives with the ideas and experiences of non-native international faculty.

Understanding how these native and international faculty with different educational and professional backgrounds have built up different perspectives of teaching will shed light on developing alternative approach to teaching English in the Korean EFL settings.

\section{Focus on Teacher Perceptions}

Since 1990's teacher education research has placed more emphasis on how teacher's cognition, knowledge, and experiences influence and shape their teaching practice. This new line of teacher education research began to highlight the ways teachers are shaped by their prior experiences as students (Peacock, 1999; Samimy \& Lee, 1997), their personal practical knowledge (Connelly \& Clandinin, 1985), their values and beliefs (Pajares, 1992), and the context in which they are engaged (Feryok, 2008; 
Mattheousdakis, 2007; Polat, 2010). Those recognized that "teachers are central to understanding and improving English language teaching" (Freeman \& Johnson, 1998, p. 401), and teachers' beliefs about teaching and past experiences as learners are "instrumental in shaping how they interpret what goes in the classroom" (Freeman \& Johnson, 1998, p. 401). In light of this emerging trend in teacher education, teacher education research has begun to acknowledge the importance of teacher cognition, knowledge, and beliefs.

The focus of research on language teaching has shifted from investigating merely behaviors of teachers to also investigating the cognition of teachers that prompts such behavior (Yook, 2011). As part of this shift, teachers' beliefs have been recognized as an important variable in language teaching (Renzaglia, Hutchins, \& Lee, 1997; Stuart \& Thurlow, 2000). Teachers have been shown to be decision makers in creation of classroom realities (Freeman \& Johnson, 1998; Richards, 1996;

\section{Research Methods}

\section{Participants}

There were 71 international faculty who participated in this comprehensive research for enhancement of English teaching and learning at the university. All 71 faculty were invited to fill in the survey form created and shared on google. Details of participants are as follows.

Nationality. As for nationality of faculty, there were 17 different countries, out of which the largest group came from USA (33\%), while the second largest group came from the Philippines (31\%).

Gender. As for gender, there were $59 \%$ of male and $41 \%$ of female faculty.

Age. When it comes to ages, it is intriguing to note that the largest segment
Richards \& Lockheart, 1996; Woods, 1996), and acting in "the light of their own beliefs, attitudes, and perceptions of the relevant teaching situation" (Tudor, 2001, p. 17). Johnson (1994) predicts that "teachers' beliefs would ultimately become one of the most valuable psychological constructs for teaching and teacher education" (p.439).

The general consensus in the literature has been that teachers' beliefs have a critical impact on the way they learn how to teach, the way they teach in the classroom, and the way they perceive educational innovations (Borg, 2001). This growing consensus signals that exploring teachers' beliefs is particularly important in context where educational reform is a matter of serious concern. The successful implementation of any educational innovation is dependent upon how teachers perceive the reform and how their perceptions can be influenced by their beliefs about education. That is, the success of educational reform is contingent on teachers' educational beliefs (Yook, 2011).

(40\%), were made up of faculty aged 40 to 49 , with the second largest segment (36\%) being aged 30 to 39 .

Academic Level. When it comes to academic credentials, there were some surprising results. The vast majority of international faculty had a Masters degree $(38 \%)$. However the second largest segment, by the slim margin of $1 \%$, had a Bachelors degree (19\%), with the third segment having $\mathrm{PhDs}(18 \%)$. However, it is also important to highlight that $18 \%$ of international faculty had TESOL/CELTA or other certificates. But whether the certificates are held by those with a Bachelor, Masters, or $\mathrm{PhD}$ degree is uncertain. 


\section{Data Collection}

In order to collect data for analysis, a comprehensive google survey form was created by one of the international faculty whose major was software engineering as well as English education. Since the main researcher who coordinated the research process had built a solid rapport and trust with the faculty, they all agreed to share their thought and ideas for educational enhancement. Hence, the survey form was shared with all faculty a duration of two weeks for them to input their thoughts and ideas in it. All quotes in the analysis and discussion section are not the results of oral interview but participants genuine written statements on the survey form.

The survey consisted of 45 questions concerning teaching experience, teaching/learning philosophy, teaching skills, and suggestions for enhancing students' communicative abilities. First, as for teaching experience, the following questions were asked: How long have you taught English? How long have you taught content subjects? What motivated you to become a teacher? What motivated you to teach English in Korea? What do you consider to be the most significant experience you have had in teaching English?

Second, as for teaching philosophies, the following questions were asked: What is your view of language? What is your view of language learning? How would you describe yourself as an English teacher? How do you understand Communicative Language Teaching (CLT)? How do you apply CLT in your classroom? Do you have any maxims or guiding principles which sum up aspects of your approach to the teaching and learning of English? If so, what are they?

Third, in terms of teaching techniques and skills, the following questions were asked: In your own teaching, to what extent do you seek to promote the development of your students' explicit knowledge about English? How do you handle learner's errors? What are the basic teaching materials you use for your classes? What kind of programs do you intend to pursue for your professional development? What do you think about students' silence in class and what's your way to promote communication in the class? To what extent do you use technical terminologies in your teaching? What is the rationale for the use/non-use of grammatical terminology?

Lastly, in terms of suggestions for innovation in English teaching, the following questions were asked: How do you find your students' motivation with respect to learning English? What do you think is the best way for the faculty to help students overcome their obstacles and improve their communicative skills in English?

\section{Analysis and Discussion}

As many of the survey items were open-ended, it was thought whatever they 'say' in the survey form count and are valuable as such. Thus, it was decided to present quantitative results followed by qualitative description and discussion. It was believed by the researcher that paralleling analysis, description, and discussion in the same section would contribute to authenticity and validity in a study of rather collaborative and qualitative nature.

\section{Perceptions about Second Language Learning Experience}

BEYOND WORDS Vol. 8, No. 2, November 2020 
When it comes to the second section of the survey, Learning and Research, a number of questions were asked including experience of learning a second language and its effects on English teaching/learning, and their perception on differences between teaching in Korea and other ESL/EFL contexts.

Positive Effects of Second Language Learning experience. As for the area of learning and research the international faculty was interested in, as shown in Figure 1, the largest was social science (24\%), followed by English (21\%), Humanities (16\%), TESOL (14\%), Education (13\%), and Other $(12 \%)$. With the second area of interest English, it is then interesting to note that $87 \%$ of the international faculty had learned a second language.

This should not be too surprising since $33 \%$ of the faculty, come from the USA, where Spanish is often taught at middle or high school. Another $31 \%$ of the faculty came from the Philippines, where there are two official languages and twelve official auxiliary languages. Then there are also a number of faculty that come from countries where there are two or more official languages, like Canada (French and English), Pakistan (Urdu and English), Cameroon (French and English), Haiti (Haitian Creole and French), India (Hindi and English), South Africa (English and 10 other official languages), etc. It is also relevant to highlight that a number of international faculty also either learned or are busy learning Korean as a second or third language.

When discussing positive aspects of having learned a second language, a number of interesting comments were made by the international faculty. Firstly, it was mentioned that having learned a second language helped the faculty empathize with their students. It meant that they could understand the difficulties that students face in learning English. Then there were the positive personal aspects to learning a second language such as the ability to understand and engage in a new culture, and the availability of new opportunities, thanks to globalization. When discussing the negative aspects of learning a new language, difficulty in forming sounds different from one's mother tongue, difficulty in correctly pronouncing words were mentioned. Two other negative aspects were related to trends of globalization: brain drain and the loss of intellectual capital, and the loss or extinction of minority languages in the push to adopt English as the lingua franca.

Similarities and Differences between Teaching in Korea and Other EFL/ESL Contexts. When asked if they had taught English in other EFL/ESL contexts, a staggering 63\% answered yes. When asked what was similar, there was a wide variety of answers. Some followed the philosophy that people are people. Students are all the same, all over the world. Others pointed out similarities like the use of route memorization, students translating English into their native tongue and then translating their answers back into English, difficulties in pronunciation. Others pointed to a lack of motivation. A few examples are shown below:

(Prof. X). "Students, for the most part, are the same everywhere."

(Prof. ID). "Students tend to memorize vocabulary first, and try to translate words according to the structure of their own language"

(Prof. Y). "The content being taught. The core of teaching English to foreign learners is for them to be equipped with the necessary skills to communicate confidently using the language." 
(Dr. K). "Almost everywhere you go in the world, students are not used to using English as a means of communicating with others. Instead it's viewed as a formal (often obligatory) object to be studied."

(Prof. AA). "The large-scale lack of motivation is very similar between the Korean and Chinese contexts. Also, the preference for students to prefer rote grammar and vocabulary learning over a more conversational style. In both contexts the students were generally very unwilling to speak in class." [A number of other faculty echoed this sentiment.]

(Dr. L). "Students in Korea, Vietnam, and Thailand love to gain high scores at the end of the course though they sometimes did not work as hard as they could to afford it"

When it came to differences, there was a wide variety of answers. Some faculty pointed to different motivation levels, others that student' struggling with poverty was not a concern in Korea. A positive aspect of teaching in Korea was that there was much more freedom in Korea when it came to teaching materials and curriculum. A few examples are shown below:

(Dr. H). "Korean students (GU) lack motivation and desire to learn English. Most of them are not interested in learning about western culture and are not as open and eager to learn (compared to Chinese students)." [A number of other faculty echoed this sentiment.]

(Prof. AB). "The plus point for an English teacher in Korea is that its syllabus free teaching i.e. the teacher is free to teach according to the needs and level of the learners."

(Prof. V). "In different parts of Korea, it's hard to get a lot of exposure to English outside of the classroom setting. I tutored international students in the States for part time jobs. They were able to get a lot of practice time in English if they choose to venture out and meet other English speakers instead of staying with their own cultural community."

(Dr. M). "My experience of teaching in Middle East says that Korean EFL learners follow their instinct for perfection and avoiding unnecessary mistakes. Comparing to Middle Easterners, they are less willing to take risk to speak English while their urge for progress makes them eventually succeed to reach their goals."

(Dr. E). "English is much more difficult for Korean students because their language is so different from English; also, they have been less exposed to people, events and cultures outside Korea."

It is noted that positive effects of learning a second language in teaching English and comments about similarities and differences between teaching English in Korea and in other EFL/ESL contexts have implications for consideration in hiring international faculty.

\section{Perceptions about Teaching/Learning Philosophy}

In this section of teaching/ learning philosophy, a number of questions were asked, including view of language, view of language learning, view of teacher and student roles in the class, attitude toward CLT as well as their general maxims for teaching.

\section{View of Language}

Firstly, when it came to views on language, as shown in Fig. 1, the vast majority of faculty $(62 \%)$ considered it to be a combination of structure, communication, and social interaction. This result indicates 
the fact that the majority of the faculty has a balanced understanding of the properties of language. If they had been hired only because they were native speakers or second language users without proper academic credentials, it is thought there would have been more percentages on the 'language as structure' choice. If a professor has a perspective of language as structure only, language classes will be filled with more or less rule-governed but 'drill-and-kill' activities, which will lead to de-motivation and frustration on the part of students. In this sense, it is notable that there was only $2 \%$ of faculty with language as structure perspective. It is argued though that this needs further investigation by comparing this data with other qualitative data such as ethnographic interview, participant observation, or teacher diaries, which stands beyond the scope of the current study.

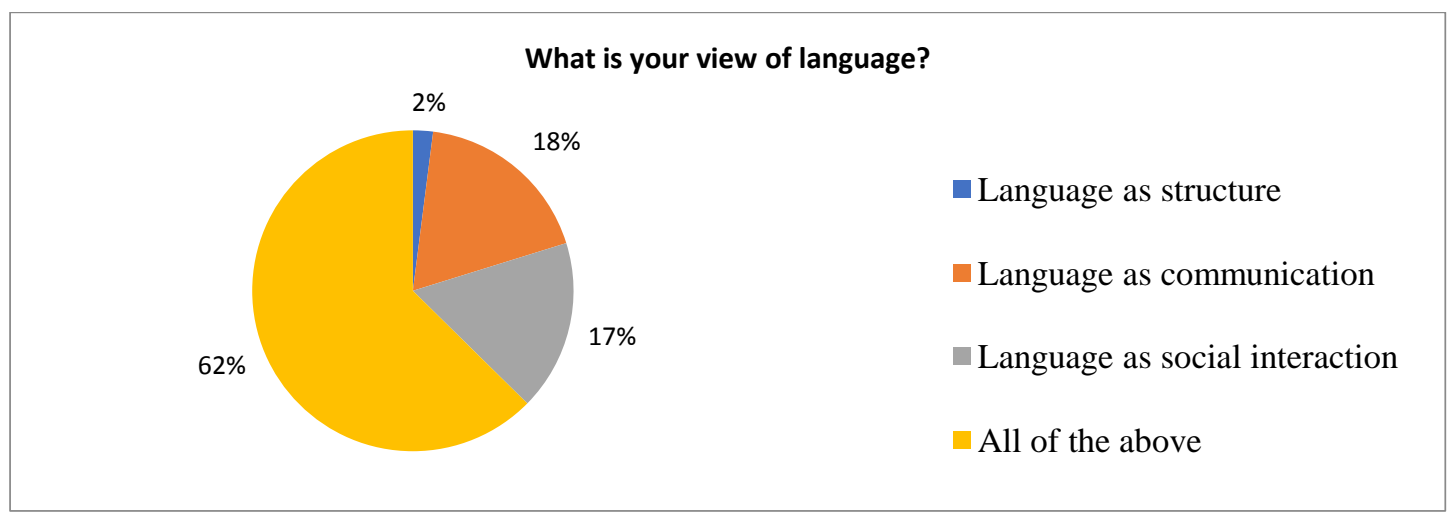

Figure 1. View of Language

View of Language Learning. Secondly, as for views on language learning, as shown in Fig. 2, the majority of the faculty $(55 \%)$ considered it as influenced by a combination of behaviorism (a patterned behavior), cognitivism (a cognitive tool), innatism (an innate ability), constructivism (a socially constructed tool), rather than any one of them. This result is consistent with the views on language.
Attitude toward Communicative Language Teaching. There was a lengthy dialog and differing views on Communicative Language Teaching (CLT) and how faculty applies CLT in their classrooms. There were a number of faculty that were unaware or not familiar with the approach. While among those that utilized the approach in their classrooms, essentially it was used to supplement, or as a way to engage the students within, a student-centered classroom. A few examples are shown below: 


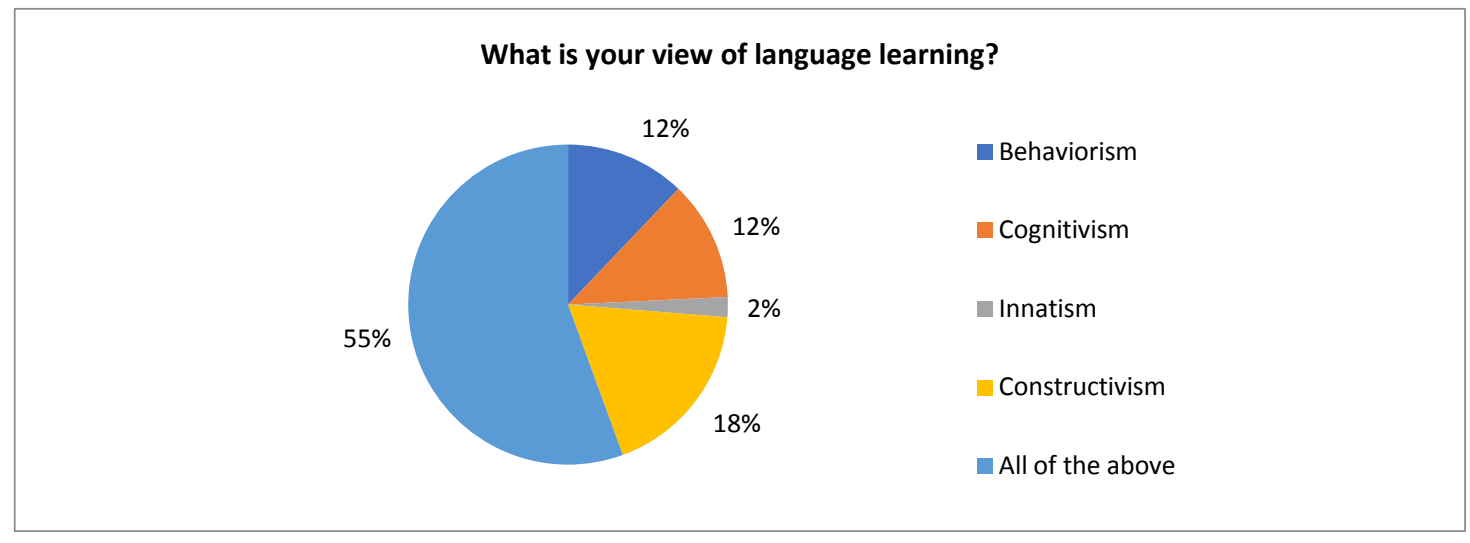

$\mathrm{F}$ igur e 2. Vie

w of Language Learning

(Prof. II). "Well, it depends on what form of CLT as there are two: a hard CLT and a soft CLT. I tend to not agree with the hard CLT as it forbids error correction and grammar and as several studies have shown that students who have been trained using exclusively the hard CLT can be effective communicators but struggle with accuracy. On the other hand, the soft version of the CLT emphasizes communication but leaves room for some grammatical instruction (as long as such instruction is aiming at helping the learner to better communicate their ideas) and for error correction (which is needed especially in academic settings).

(Prof. J). "CLT is a method used to engage students in communicative activities/situations applying the language rules and structures. I used CLT to encourage students to communicate and relate their experiences to the situations provided relevant to the language focus."

(Dr. H). "I don't agree with the approach. I have developed my own method."

(Prof. K). "Not familiar with it." [A number of other faculty echoed this sentiment.]

(Prof. P). "For me, it is to give the students structure (very light) and motivation to speak in English. In Korean contexts, it often means offering a subject as well, to get the conversation going. Once conversations are moving, as long as they continue mostly in English, the class purpose is being achieved. When distractions or the end of a conversation pulls the students away from English, I introduce another topic that extends well from the first offered topic, usually gleaned from listening to student discussions and interacting with them."

(Dr. M). "To apply CLT in my class, I teach language components (language competence), try to teach different social roles my students need to adopt (sociolinguistic competence), teach them how to read and write (discourse competence) and finally couch them how to overcome the communication problems (strategic competence) relatively to the level of my students."

(Prof. L). "A basic definition of "Communicative Language Teaching" is simply using spoken language to learn English, rather than methods like writing, rote memorization, etc. Students often ask me for "free talking" in my class, which is related to CLT. The problems I see are the fact the students are often not at the level to 
"free talk", so need to go back and learn the vocabulary, grammar, etc. to achieve the ability to "free talk". The other problem is related to "practice makes perfect". Some teachers/professors believe that as long as students are speaking English in a way that the teacher/professor understands, it is then "correct" English. I disagree. So, just talking through the CLT method will not result in CORRECT English unless every mistake in grammar, pronunciation, etc. is corrected."

(Prof. Q). "I understand CLT as an approach that encourages students to actually use language in realistic situations to achieve certain goals. It is an attempt to make language study less abstract, more concrete, by setting some sort of goals for students that require the use of some target language."

Maxims of Teaching. When the faculty was asked if they had any maxims or guiding principles which sum up aspects of their approach to the teaching and learning of English, a number of things emerged. There were some that view maxims as being too simplistic. A number of maxims could be summarized as variations on the golden rule. "Do unto others, as you would have done unto you." There were also a number that pointed to using humor in the classroom. A few examples are shown below:

(Prof. I J). "My guiding principle in teaching is, "The best teacher teaches from the heart and not from the books."

(Prof. IK). 1. "A happy student is a good learner." I think Krashen's Affective Filter Hypothesis is right. We definitely are more disposed to learn when we feel safe, are in a happy, relaxed atmosphere. 2. "Practice don't memorize". Languages are learned through practice. Not practice in the audiolingual sense of the term, but the sense of using the language for purposeful communication. It's no use trying to memorize vocabulary. 4. "Be fearless and never walk that road alone". People who are less inhibited and who are not afraid of making mistakes and looking stupid tend to be more successful language learners as they tend to use the language more regardless of mistakes they make; and as they keep fixing those mistakes along the way, they improve and ultimately acquire the language. Also, a language is meant for communication, so having a buddy (preferably a fellow learner) with whom we can practice on a regular basis can be of great help.

(Prof. M). "I believe that here in Korea, most students at the college/university level have a vast vocabulary. Many of them have been studying English for many years and the amount of English knowledge that they have incurred is huge, even if they don't know it. I think the biggest problem in English teaching is the lack of confidence that most students suffer from. My approach in the classroom is to bring out the knowledge that the students already have."

(Dr. K). "Teaching and learning are very complex affairs and maxims too often reduce them to snake oil."

(Prof. L). "Be motivated by love, respect, and understanding in all you do, teaching and all other things."

(Prof. AD). "A guiding teaching principle I have is that everyone learns better with laughter, because it lowers the stakes for making mistakes and encourages more risk-taking and spontaneity."

(Prof. Z). Students are people first. Just let the student be themselves yet guiding and nurturing them along the way. 2. Using creative teaching methods that will aid in the classroom. 3. Using constructive criticism as a platform to become a better teacher. 4. Enjoy and have fun teaching the 
students.

(Dr. N). 1. Encourage, 2. Be patient, 3. Focus on participation, 4. Let them do the things, just guide them or watch, 5. Bring examples from the real world/practical things, 6. Give everyone a chance

\section{Perceptions about Teaching Techniques/ Skills}

In this section on teaching skills and techniques, a number of things were asked including attitudes toward teaching explicit knowledge of English, attitude about error treatment, attitudes toward professional development, attitudes toward promoting communication in the class, attitude about grammatical terminology in the class.

Attitudes toward teaching Explicit Knowledge of Language. When asked "In your own teaching, to what extent do you seek to promote the development of your students' explicit knowledge about English?", the vast majority of faculty (69\%) mentioned they use explanations with examples, as shown in Fig. 3. When asked, "To what extent do you use technical (grammatical) terminologies in your teaching? What is the rationale for the use/non-use of grammatical terminology?", there were a number of differing responses from not using technical (grammatical) terminologies at all, to using it as required by the situation, through to using it extensively. The rational for the use or none use of technical (grammatical) terminologies varied from not using it at all in order to build students confidence, to only using technical (grammatical) terminologies as required in order to answer students questions, through to always using technical (grammatical) terminologies since it serves as the foundation or basis of using the English language.

\section{Attitudes toward Error Treatment.}

Interestingly in answering the question; "How do you handle learner's errors?" the overwhelming majority of faculty (77\%) chose to correct both global and local errors.

Perceptions about How to Promote Communication in the Face of Silence. When asked, "What do you think about students' silence in class, and what's your way to promote communication in the class?" There were a number of responses and a number of strategies to overcome student's reluctance to speak.

Some of the responses to students silence ranged from it being a massive problem, to silence not being a problem at all. It was generally held that silence could be an indication of a number of things. For example, student's taking time to think about a response, processing information, reflection on the lesson or material, or even student's being bored. The general consensus being that silence needed to be interpreted in light of the context. A number of strategies to overcome student's reluctance to speak were also offered; build rapport with students, make students feel comfortable in class, ask open ended questions, call on students by their Korean name to answer questions; So Young what do you think?; use scripted roll-plays, use small group or partner speaking exercises, begin with students reading aloud before engaging in free talk, let students decide what they would like to discuss or learn, utilize humor to make students feel at ease and help them realize that it is ok to make mistakes. A few examples are shown below:

(Prof. IL). "I tried to know the root cause of this problem. I talk to students after the class. Once I know I had established rapport in them, I build their confidence by asking first easier questions. In the

BEYOND WORDS Vol. 8, No. 2, November 2020 Graduate School, Widya Mandala Catholic University Surabaya 
classroom, I always go around to see that everybody is comfortable and ready to learn." [A number of other faculty echoed this sentiment.]

(Prof. IM). "The way I perceive students' silence is dependent on the context of the silence and their behavior while they are being silent. Their silence could have different meanings varying from complete disinterest, boredom, reflection, processing of information, etc. To promote communication, I ask question and get them to act out roles in various communicative situations." [A number of other faculty echoed this sentiment.]

(Prof. J). "I don't like to have silence in the classroom. To me it is a sign that I am speaking too much and not getting them active and engaged enough. I usually do small group or partner speaking activities to get them to start communicating." [A number of other faculty echoed this sentiment.]

(Prof. K). "Have them read something so they can get used to speaking class without at first having to worry about creating their own sentences."

(Prof. S). "I think silence isn't always bad. It gives time to think. I first ask for volunteers, then call on some of the active students first and then move to the rest of the students. I try to ask everyone. If someone doesn't have anything to say, I ask them if they want to pass or come back to them later."

(Dr. J). "I try to make them feel comfortable and at ease, that makes them communicate better in class."

(Prof. T). "Student silence is a massive problem, but also a great challenge. In order to promote communication I try to give the students a lot of responsibility in selecting what they would like to discuss/learn about etc. I also try to include as many openended questions as possible. I have found from my own experience that discussing the local culture of the students - and particularly my own personal views and experiences of it - is often a great catalyst for evoking a response from the class." [A number of other faculty echoed these sentiments.]

(Dr. D). "It's not an issue because I use CLT methods that keep them interactive. Also silence doesn't mean student is not interacting or learning. The student might be processing the information." [A number of other faculty echoed this sentiment.]

\section{Suggestions for Innovation in English Education}

In this section, perceptions about obstacles to effective communicative teaching, those about students' level of motivation and lack of communicative abilities are discussed. Following that discussion, suggestions from the faculty for enhancing students' communicative abilities are presented.

Obstacles to Innovation. "What are some obstacles to your teaching English to your students?" was the question asked. It was shown that the greatest obstacle (48\%) was having mixed levels of students in the class, followed by lack of teaching equipment in the class (18\%), strategies to motivate students (14\%), small size of class (7\%), and other regions (13\%).

Students' Motivation toward Learning English. When asked about how they find GU student's motivation with respect to learning English, the majority (56\%) found their students to be somewhat motivated, as compared with a little motivated (19\%), well-motivated (18\%), and unmotivated $(7 \%)$.

Perceptions about Students' Lack of Communication Ability. When asked about the percentage of students who did 
not have any communication ability in their class, faculty's response varied depending on their classes. $39 \%$ of faculty mentioned less than $20 \%$ of students were lacking in communication ability, while $7 \%$ of faculty mentioned more than $50 \%$ of students were lacking in communication. There were $23 \%$ of faculty who mentioned 20 to $30 \%$ of students were lacking in communication skills, while $17 \%$ of faculty mentioned 30 to $40 \%$ of students were not able to communicate well.

A Need for Innovation in General English Education. When asked about the best way to help GU students overcome their obstacles and improve their communication skills in English, the majority of faculty (44\%) pointed to innovation in the general English education program, followed by innovation in extracurricular program (17\%), and innovation in major English program (13\%). When asked about regular courses which they thought were needed to improve students' English proficiency, the majority (11\%) pointed to the conversation course, "Enjoy Talk." Out of the remaining courses there was an even spread of $9 \%$ for each of the following courses; Easy English interview, English through speech, TOEIC speaking, Understanding multi-cultures.

Differing Views on Teaching Major Courses in English. The next question elicited an unexpectedly strong response. The question was, "Do you think it is necessary to have major courses taught in English by native speaker professors?" When it came to agreement, $40 \%$ of faculty agreed; $23 \%$ of faculty agreed somewhat, with $17 \%$ strongly agreeing. With disagreement, $42 \%$ of faculty disagreed; $29 \%$ of faculty disagreed somewhat, while $13 \%$ disagreed strongly.
Of those that disagreed (42\%), $9 \%$ were from Philippines, $2.8 \%$ were from the USA, $1.4 \%$ was from Canada, $0.7 \%$ was from Australia, 0.7\% was from Cameroon, $0.7 \%$ was from India, $0.7 \%$ was from Malaysia, $0.7 \%$ was from Nepal, $0.7 \%$ was from Nigeria, $0.7 \%$ was from Pakistan, and $0.7 \%$ was from Sri Lanka. What is very interesting is that of those that agreed (40\%), $11 \%$ were from the USA, $3.5 \%$ were from Philippines, $1.3 \%$ was from Canada, $0.7 \%$ was from Pakistan, $0.7 \%$ was from South Africa, $0.7 \%$ was from the UK, and $0.7 \%$ was from Vietnam. A few examples of comments are shown below:

(Prof.AE). "In my humble opinion, the effectiveness of language instruction does not depend solely on the idea that the professor is a native speaker but also on other factors such as teaching strategies, attitudinal factors, etc." [A number of other faculty echoed these sentiments.]

(Prof. IN). "I think students need to learn English from both native and nonnative speakers. English is more commonly spoken as a second language than as a first language. They can learn standard forms of English from native speakers, but they also need to hear different accents and dialects in order to communicate when traveling abroad."

(Prof.AD). "The major or core courses can be taught by anyone who has the skill and the passion to impart knowledge to students. Of course, it would be better to have content professors but other professors can brush up on their reading and grasp the essentials. I've done that in my class English Conversation for Majors. As long as the professors never stop reading and never stop learning, he/she can get by.",

(Prof. P). "The right professor/teacher with an adequate knowledge/experience 
level and ability to communicate with students is all that is needed." [A number of other faculty echoed these sentiments.]

(Prof. L). "I don't think that any student should be forced into learning something like a language. It will do nothing more than hinder the learning process. Content courses may be difficult for some students to understand even in their own native language. In my view, the teaching of content courses in English should be made available only based on the level of student interest in such courses."

(Prof. AD). "I was reading about France's English language instruction, which is done mostly through content courses being taught in English with explicit grammar instruction de-emphasized. The article mentioned the degree of fluency that most students achieve through this type of English instruction. I think it would allow the students to be immersed in the vocabulary that would be best targeted to what they want to know and what they will use most."

(Prof. Y). "Immersion can be a valuable teaching tool. Most students speak English during their elective classes and maybe minimal during this time. This could be why some students seek to talk and improve their English through the mentor program or some other venue because they are seeking more exposure to interacting and being able to adapt to speaking English on a global scale."

(Dr. Q). "In general this is a decent idea, in particular at GU with its massive and diversely majored foreign teaching faculty this tract is not only ideal it is a practical method to promote GU's uniqueness."

(Prof.AF). "Major subjects are content oriented and content has to be taught not only practiced like a language class room. I believe that major courses which are content oriented should be taught by Korean professors."

(Prof. P). "I don't believe there are enough students who have a high enough level of English, for this to be beneficial."

(Dr. E). "Students who have contact with major courses in English will be better able to function in a world that is increasing using English as the lingua franca of global communication. Students will improve critical thinking skills, terminology, and content in specific areas of knowledge if they are exposed to major content courses in English. Other nations are well ahead in English acquisition and use in major courses. South Korea must continue to invest in this pursue it."

It is interesting to note that there was a negative response to the phrase native speaker professors, from the question; do you think it is necessary to have major courses taught in English by native speaker professors? When asked to explain the reason for their answer. There were a number of interesting responses and interestingly a backlash to the phrase "native speaker professors", from the question;"do you think it is necessary to have major courses taught in English by native speaker professors?"

South Korea has held for a long time, the stance that it wants to employ native English speakers; being people that originating from the USA, Canada, UK, Australia, New Zealand or South Africa. So there is an understandable backlash from professors from other countries like, the Philippines, Sri Lanka, and India. Who even though English is not their first language, it is their second language. They feel that they are fluent in both languages and able to teach effectively in both as shown in excerpts below: 
(Prof. I. Philippines). "Non-native English speaking professors are as qualified as native English speaking professors to teach any English courses."

(Prof. IO. Philippines). "Other nationalities though English may not be their native language may articulate better and can even construct essays and the like, flawlessly, compared to native English speakers."

(Prof. J. Philippines). "If the native speaker is competent enough to teach, that's acceptable. However, in some cases, being a native speaker does not guarantee competence in the mastery of the content and the appropriate teaching method to be used. Furthermore, there are also other nationalities who are as qualified."

(Dr. P. Philippines). "I somewhat disagree because for me the students need a professor who is passionate about having his/her students learn more than a professor who speaks the language fluently."

(Prof. L. Philippines). "The effectiveness of teaching of how to communicate in English is not dependent on whether or not you are a native speaker. For while being a native speaker is an advantage, English language teaching, or the teaching of any other course for that matter, requires adequate knowledge in methodology and teaching principles. Most of all, teaching requires the heart. Only when one has genuine concern for learners will there be a mutually productive teaching-learning experience."

(Prof. X. Sri Lanka). "I have produced enough good results throughout my experience overseas even though I'm not a native speaker but My fluency and accent of the language is similar to the native speakers. In addition to this my major of first degree in English master in linguistics British council trained and my P.G.D.E(TESL) qualification."

(Dr. D. India). "It's okay to have class in English but there is no need to have native English speakers. Also, there is always a question mark on who is the native speaker because when a language becomes global no one can claim the authority of language."

\section{Conclusions and Suggestions for Further Research}

\section{Conclusions}

The current study investigated perceptions of international faculty at a local university in S. Korea. The survey consisted of 45 items which tried to investigate the perceptions about effects of international faculty's previous second language learning experiences, their views on differences between teaching English in Korea and other ESL/EFL contexts, their perspectives on language, language learning, and roles of teacher and students in the classes, their specific views on CLT, on their position on the teaching explicit knowledge in English instruction and the related use of grammatical terminologies in the English instruction. The survey also investigated the faculty's perceptions about their students' problems in learning English, level of students' motivation, lack of communicative abilities, and ways of error treatment.

The results of the survey are summarized as follows:

1) Relevant second language learning experience helps improve quality of instruction since those experiences are said to serve to understand students' difficulty in learning English;

2) A positive aspect of teaching in Korea was that there was much more freedom in Korea when it came to teaching 
materials and curriculum;

$3)$ The vast majority of faculty $(62 \%)$ considered language as a holistic combination of structure, communication, social interaction;

4) The majority of faculty $(55 \%)$ considered language learning process as interaction of behaviorism (a patterned behavior), cognitivism (a cognitive tool), innatism (an innate ability), and constructivism (a socially constructed tool);

5) The role of teachers was that of facilitators with the emphasis on guiding students in a student- focused class;

6) As for the use of CLT, admitting that there were a number of faculty who were not familiar with it, it was found that for those utilizing the approach, it was used to supplement, or as a way to engage the students within a student centered classroom;

7) As for guiding principles of teaching, a number of maxims could be summarized as variations on the golden rule: "Do unto others, as you would have done unto you.";

8) As for teaching explicit knowledge of English there were a number of differing responses from not using technical (grammatical) terminologies at all, to using it as required by the situation, through to using it extensively;

9) As for error treatment, the overwhelming majority of faculty (77\%) chose to correct both global and local errors;

10) As for dealing with the issue of silence in the classroom, there were a number of strategies being used by the faculty to overcome student's reluctance to speak, such as letting students decide on what they want to discuss or learn, utilizing humor to make students feel at ease, and above all, helping students realize that it is ok to make mistakes;
11) It was found the greatest obstacle faculty encountered in teaching English was having mixed levels of students in the class;

12) As for the best way for the faculty to help students overcome their obstacles and improve their communication skills in English, the majority of faculty (44\%) pointed to innovation in the general English education programs.

13) As for regular courses they thought were needed to improve students' English proficiency, the majority (11\%) pointed to the conversation courses such as "Enjoy Talk.", "Easy English interview", "English through speech", "TOEIC speaking", and "Understanding multicultures";

14) As for teaching content subjects in major courses, $40 \%$ of faculty agreed while $42 \%$ disagreed.

\section{Suggestions for Further Research}

The diverse caliber of faculty nationality with various differing educational and professional experience will provide useful ideas for consideration in enhancing English education in other higher institutions. What follows are some limits and points of departure for further research:

1) It is noted that hiring faculty with relevant second language learning experience will help improve quality of instruction. Those with second language learning experience will be more open, liberal, and sympathetic to the learning difficulties faced by students.

2) Though views on language and language learning were found to be holistic, each of the items needs to be further investigated by other instruments such as diaries, ethnographic interviews, and participant observation.

3) This study did not include observed practices through classroom observation. Thus, faculty's stated views on language 
and language learning need to be compared with actual observation data to corroborate whether their perceptions are consistent with their own teaching behaviors.

4) In order to develop a more effective
English language programs that will enhance students' communicative abilities, needs assessment must be implemented not only with the faculty but involved students as well.

\section{(C) Dr. Sang-Ho Han}

Dr. Sang-Ho Han is a professor at Logos College of General Education at Gyeongju University, South Korea. He entertains his learners with the wisdom inspired by the philosopher of Laotzu's spontaneity. As a leading author of Korean Highschool Korean English Textbooks, he serves as Presidents of Korea TESOL and PKETA (Pan Korea English Teachrs Association_. His academic interests are glocalization of English education, the Beginner's Mind Approach teaching, wavicle perspectives in ELT, and Pedagogy of Inclusion.

\section{References}

Borg, M. (2001). Teachers' beliefs. ELT Journal, 55(2), 186-188.

Breem, M. P., Hird, B., Milton, M., Oliver, R., \&Thwaite, A. (2001). Making sense of language teaching: Teachers' principles and classroom practices. Applied Linguistics, 22(4), 470-501.

Chin, J. (2002). Native English-speaking teachers' perceptions of learning and teaching EFL in Korea. English Teaching, 57(2), 113-135.

Choi, J. Y. (2006). Beliefs about English learning and teaching: from teacher learners' perspectives. English Language Teaching, 18(2), 1-24.

Crookes, G. (2009). Values, philosophies, and beliefs in TESOL. Cambridge: Cambridge Univ. Press.

Feryok, A. (2008). An Armenian English language teacher's practical theory of communicative language teaching. System, 36, 227-240.

Freeman, D., \& Johnson, K. (1998). Reconceptualizing the knowledge-base of language teacher education. TESOL Quarterly, 32(3), 397-417.

$\mathrm{Gu}$, Q. (2010). Variations in beliefs and practices: Teaching English in crosscultural contexts. Language and Intercultural Communication, 10(1), 32-53.
Johnson, K. E. (1994). The emerging beliefs and instructional practices of pre-service English as a second language teachers. Teaching and Teacher Education,10(4), 439-452.

Kim, S. H. (2011). Exploring native speaker teachers' beliefs about learning and teaching English. English Teaching, 66(2), 123-148.

Renzaglia, A., Hutchins, M., \& Lee, S. (1997). The impact of teacher education on the beliefs, attitudes, and dispositions of preservice special educators. Teacher Education and Special Educations, 4,360377.

Richards, J. (1996). Teachers' maxims in language teaching. TESOL Quarterly, 30(2), 281-296.

Richards, J., \& Lockheart, C. (1996). Reflective teaching in second language classrooms. Cambridge: Cambridge University Press.

Shin, S. J. (2002). An ethnographic study of Asian English teachers' beliefs. English Teaching, 57(2), 91-112.

Stuart, C., \& Thurlow, D. (2000). Making it their own: Pre-service teachers' experiences, beliefs, and classroom practices, Journal of Teacher Education,51(2), 112-121.

Tudor, I. (2001). The dynamics of the language

BEYOND WORDS Vol. 8, No. 2, November 2020 Graduate School, Widya Mandala Catholic University Surabaya 
classroom. Cambridge: Cambridge Cambridge: Cambridge University Press. University Press.

Yook, C. M. (2011). Interactions between

Woods, D. (1996). Teacher cognition in language teaching: Beliefs, decisionmaking and classroom practice. beliefs, practices, and perceptions of Korean EFL teachers. English Teaching,66(4), 3-26. 